\title{
"PAREM DE NOS MATAR": A BIONECROPOLÍTICA GENDERIZADA E A PERSISTÊNCIA DE MULHERES INDÍGENAS E NEGRAS NA AMÉFRICA LADINA
}

Fátima Lima'

Julia B. Gambetta²

Resumo: Esta reflexão toma três dispositivos analíticos: (a) o assassinato da ativista indígena Berta Cáceres, no dia 2 de março de 2016 (Honduras); (b) a prisão da líder indigena Milagro Sala, em 16 de Janeiro de 2016 (Argentina); e (c) o assassinato da vereadora e militante Marielle Franco, no dia 14 de março de 2018 (Brasil), para pensar a constituição de uma bionecropolítica genderizada que tem nas relações étnico-raciais um elemento central que produz e legitima o extermínio de mulheres. $\bigcirc$ objetivo é entender como diagramas de poder são forjados e operam uma bionecropolítica genderizada na América Latina.

Palavras-chave: Bionecropolítica; Gênero; América Latina.

Abstract: This paper is grounded on three analytical standpoints: (a) the murder of indigenous activist Berta Cárceres on March 2 ${ }^{\text {nd }}, 2016$ in Honduras, (b) the imprisonment of the indigenous leader Milagro Salas on January $16^{\text {th }}$, 2016 in Argentina, and (c) the murder of congresswoman and activist Marielle Franco on March 14 $4^{\text {th }}, 2018$ in Brazil. These cases are used to analyze the forging of a gender-based form of bio-necropolitics in which ethnicity and race serve as central elements which produce and legitimize the obliteration of women. Our aim is to understand the power relations which are forged within and mobilize gendered bio-necropolitical arrangements in Latin America.

Keywords: Bio-necropolitics; Gender; Latin America.

\footnotetext{
1 Professora associada na Universidade Federal do Rio de Janeiro (UFRJ) de Macaé, Brasil. E-mail: fatimalima4@gmail.com. Orcid: 0000-0002-9449-2514

2 Professora adjunta nas Faculdades Integradas Maria Thereza, Brasil. E-mail: juliabgambetta@gmail.com. Orcid: 0000-0001-9578-9937
} 


\section{Amolando escolhas: elementos epistemo-metodológicos}

Flor del Alto Perúl No hay otro capitán/ Más valiente que tú/ Oigo tu voz/ Mas allá de Jujuy/Y tu galope audaz/ Doña Juana Azurduy/ Me enamora la patria en agraz/ Desvelada recorro su faz/ El español no pasará/ Con mujeres tendrá que pelearl [...] Préstame tu fusil/ Que la revolución/Viene oliendo a jazmín.

Félix Luna, Juana Azurduy ${ }^{3}$

Na noite de 14 de março de 2018, uma mulher negra, bissexual, de origem de favela, mãe, vereadora, militante dos direitos humanos, foi brutalmente assassinada no bairro Estácio de Sá, na cidade do Rio de Janeiro. O assassinato de Marielle Franco e do motorista Anderson Gomes, no começo da noite do dia 14 de março, em uma das maiores cidades do Brasil, expôs ao mundo a gravidade desse episódio, tornando visíveis as vulnerabilidades presentes na vida das mulheres no Brasil e na América Latina, principalmente as que atuam na agenda dos direitos humanos e da justiça étnico-racial e de gênero. Marielle Franco havia saído de uma atividade de trabalho numa organização não governamental voltada para o cuidado de mulheres negras quando foi brutalmente executada. A partir de então, para toda uma população e para as mulheres - em especial as negras e as militantes em diferentes agendas sociais -, dores, incertezas e inseguranças se tornaram mais contundentes. Marielle Franco tinha 38 anos quando foi assassinada. Tinha voz forte na luta pelos direitos humanos, mais de vinte projetos apresentados em pouco tempo de mandato na Câmara de Vereadores da cidade do Rio de Janeiro, era uma parlamentar exemplar, com cerca de 46 mil votos. Até a escrita deste texto, continua a ecoar no Brasil e no mundo: "Quem matou Marielle?", "Quem mandou matar Marielle?". Até agora, dois suspeitos de executar o assassinato de Marielle Franco e Anderson Gomes - os ex-policiais militares Ronnie Lessa (acusado de ser o autor dos disparos) e Élcio de Queiroz (acusado de dirigir o carro) - estão presos e aguardam julgamento.

\footnotetext{
3 Letra da canção "Juana Azurduy", de Félix Luna, música de Ariel Ramírez, cantada por Mercedes Sosa. Juana Azurday nasceu em 12 de julho de 1870, em Toroca, próximo a Chuquisaca - atual Sucre -, na Bolívia. De origem indigena, participou ativamente na luta pela independência da América Espanhola. Conhecida como "Flor do Alto Peru", morreu em 1862. Seus restos foram exumados cem anos depois de sua morte e depositados em um mausoléu construído em sua homenagem na cidade de Sucre. Juana Azurduy foi nomeada General do Exército Argentino por Cristina Fernández de Kirchner, em 2009, e Marechal do Exército da Bolívia por Evo Morales, em 2011. Disponivel em: https://bit.ly/3gaAxQ4. Acesso em: 31 mar. 2020.
} 
Dois anos antes, na cidade de La Esperanza, em Honduras, no dia 3 de março de 2016, Berta Cáceres, ativista feminista, líder indígena, fundadora do Consejo Cívico de Organizaciones Populares e Indígenas de Honduras (COPINH), foi assassinada. Berta liderou diversas manifestações em defesa do meio ambiente, opondo-se radicalmente à construção do projeto hidroelétrico Agua Zarca no ocidente do seu país, entendendo que tal projeto atentava contra os recursos naturais e comprometia a vida de populações originárias. Em reconhecimento a sua incansável luta, em 2015 ganhou o prêmio Medioambiental Goldman, máximo reconhecimento mundial para ativistas do meio ambiente. Organizou e liderou, durante anos, o povo Lenca, etnia indígena que habita certas regiões em Honduras e em El Salvador, lutando incansavelmente em defesa do território constantemente ameaçado por iniciativas do governo e das elites brancas hondurenhas. Berta Cáceres descansava em sua casa quando a assassinaram brutalmente. Em 2018, foram julgados como autores do assassinato: Edilson Duarte, Henry Javier Hernández, Elvin Rápalo e Óscar Torres, que foram condenados a 34 anos de prisão pelo assassinato de Berta e a 16 anos pelo intento de assassinato de Gustavo Castro, ativista mexicano que se encontrava no domicilio de Berta Cáceres na noite do crime. Como coautores, foram condenados a 30 anos Douglas Butilo, Sergio Rodríguez Orellana e Mariano Díaz Chávez. Segundo a família da vítima, os autores intelectuais ainda estão em liberdade. Berta Cáceres deixou quatro filhos. Seu assassinato teve repercussão mundial, principalmente no âmbito dos direitos humanos e meio ambiente. Até hoje ecoa a pergunta: "Quem mandou matar Berta Cáceres?".

No mesmo ano em que Berta Cáceres era assassinada em Honduras, poucos meses antes, no dia 16 de janeiro de 2016, na Argentina, Milagro Sala, histórica dirigente do movimento Tupac Amaru ${ }^{4}$, em Jujuy (província no Norte da Argentina), foi privada da sua liberdade arbitrariamente. As acusações contra Milagro Sala e a organização Tupac Amaru entram na escalada de judicialização contra os protestos sociais, acompanhadas de uma forte campanha midiática contra os movimentos sociais. Milagro Sala, mulher indígena, foi a primeira presa política do governo de Mauricio Macri. Até a escrita deste texto, Sala se encontra com restrição de liberdade (em prisão domiciliar numa propriedade rural afastada de seu domicilio),

4 Tupac Amaru se refere tanto ao líder inca Tupac Amaru (1545-1572), liderança Inca, tanto quanto o líder indígena cujo nome original era José Gabriel Condorcanqui Nogueira (1738-1781), que acabou se denominando Tupac Amaru II, sendo uma liderança fundamental na resistência à colonização espanhola no século XVIII. O movimento desencadeado por Tupac Amaru II teve abrangência regional, extrapolando as fronteiras do Peru e influenciando diversas lutas indígenas na América latina, a exemplo da Bolivia, entre outros. 
com a saúde física e mental bastante debilitada. No atual governo do presidente da Argentina, Aníbal Fernández, o caso "Sala" foi retomado e será novamente discutido no congresso de Jujuy. Esse movimento encontra, por parte dos setores tradicionais, uma oposição forte à libertação de Milagro Sala.

Os três acontecimentos descritos são tomados como dispositivos analíticos para pensar uma bionecropolítica de gênero na América Latina. Muito mais do que tentar esmiuçar os elementos singulares constitutivos a cada um deles, o que nos exigiria outras reflexões mais específicas e contextualizadas, nosso objetivo é traçar uma linha de análise que procure trabalhar similitudes nesses três episódios. Que elementos conectam um crime numa rua da cidade do Rio de Janeiro (Brasil), outro na cidade de La Esperanza (Honduras) e uma prisão numa província argentina? Essa é a pergunta central neste artigo. Berta Cáceres, Milagro Sala e Marielle Franco constituem a materialização da interpelação constante e da afronta ao cis-heteropatriarcado racista a partir das experiências em viver como mulheres (indigenas e negra) fora do eixo privilegiado de gênero, sexualidade, classe, território, origem, entre tantos outros marcadores sociais e dinâmicos que transformam as diferenças em desigualdades, produzem hierarquias, opressões, assimetrias, violências e extermínios em contextos marcados pela colonialidade do poder e por uma bionecropolítica.

Por outro lado, não tomamos as vidas das mulheres negras, indígenas e racializadas em contexto latino-americano de forma igual e essencialista, principalmente as vidas de Berta Cáceres, Marielle Franco e Milagro Sala. Pelo contrário, entendemos estas categorias - mulher, negra, indigenas como produções históricas e sociais e como estratégias políticas em que "categorias como mulher, negro, negra, indígena, lésbica, trans nos servem somente para a articulação política, não podem ser fins em si mesmos" (CURIEL, 2011, p. 20, tradução nossa).

Esse mesmo exercício serve também para as categorias de etnia e raça, evidenciando que as estas são construções imaginárias materializadas em diferentes processos corporais e subjetivos. Defendemos aqui a ideia de que não podemos prescindir dessas duas categorias, tampouco podemos alimentar as armadilhas ideológicas que tentam restringir raça à biologia e etnia à cultura. Incorporamos a noção de relações étnico-raciais não como uma forma de dizer que são a mesma coisa, mas como uma maneira de cravar esses dois processos (o étnico e o racial) no coração da colonialidade, processos estes fundamentais para classificação, inferiorização e violências contra as 
mulheres marcadas étnica e/ou racialmente; alvos privilegiados dos discursos e práticas racistas. Pensando o contexto colombiano (marcados por conflitos armados internos), a intelectual afrofeminista Curiel (2011) mostra como as categorias de etnia e raça se relacionam, afetando fundamentalmente as mulheres afros e indigenas.

Assim, em oposição a qualquer tentativa universalista e essencialista no que refere especificamente, neste texto, a gênero e raça, evocamos como elemento que atravessa os dispositivos analíticos, a ideia do em-comum. Para Achille Mbembe (2017, p. 68-69),

O em-comum pressupõe uma relação de co-pertença e de partilha - a ideia de um mundo que é o único que temos e que, para ser duradouro, deve ser partilhado pelo conjunto de seus dependentes, juntamente com todas as espécies. Para tornar essa partilha possivel e para que se cumpra a democracia planetária e a democracia das espécies, é necessário exigir justiça e reparação.

É justamente a convicção da luta por um mundo em-comum que movimentava as vidas e agendas sociais e militantes de Berta Cáceres, Marielle Franco e Milagro Sala, aliada à busca por justiça e reparação para os povos e comunidades que, sob a égide da colonialidade e, consequentemente, da necropolítica, têm sido exterminados de diferentes formas.

Nesse sentido, no que se refere ao debate sobre a colonialidade, evocamos as reflexões do pensador peruano Aníbal Quijano. As discussões sobre o tema ganham força no diálogo com intelectuais e feministas negras latino-americanas, como Curiel (2011), bem como com a intelectual decolonial Maria Lugones, quando trazem as noções de diferença sexual e de gênero para pensar as relações entre gênero e colonialidade e, consequentemente, entre gênero e necropolítica. As reflexões de Maria Lugones (2008) sobre o que ela designou provisoriamente como "sistema de gênero colonial/moderno" é uma das ideias centrais para pensar além das discussões apresentadas por Aníbal Quijano, fazendo valer, com força, uma lente epistemo-metodológica interseccional deixando mais evidente o visivel, mas também fazendo ver as dimensões ocultas no entrelaçamento de gênero-raça, raça-gênero. Como nos diz Curiel (2011, p. 9, tradução nossa),

Uma análise das relações de sexo/gênero deve conter as maneiras como a raça se instalou nesta região que hoje se chama Latinoamerica e Caribe, e como ela tem produzido um neocolonialismo cujas maiores afetadas são as mulheres, sobretudo as 
racializadas e pobres, pois ambas as opressões, racismo e sexismo, têm estado presentes em suas vidas e suas relações.

Destacamos, ainda, como diretrizes epistemo-metodológicas, as reflexões de Lélia Gonzalez sobre a Améfrica Ladina como um espaço real e simbólico capaz de criar uma experiência em comum aos habitantes da dita América Latina, discussão esta que aprofundaremos mais adiante numa sessão dedicada às reflexões sobre amefricanidade.

As reflexões que dão força a este artigo partem do diálogo entre diferentes cursos ofertados em programas de pós-graduação (feminismo negro, latino-americano e decolonial, raça, gênero e interseccionalidade, necropolítica) com o trabalho de tese de doutorado de Gambetta (2019), que versa sobre as relações de gênero e colonialidade em contextos latino-americanos, tendo no protagonismo das mulheres elemento central. É importante ressaltar que as discussões que apresentamos aqui não têm como finalidade exaurir o tema. São caminhos que escolhemos pela força que têm de nos apresentar possibilidades de racializar as reflexões. Assim, nosso exercício é provisório, tem o limite do tempo, do formato e das escolhas, mas tem como finalidade central compor com as reflexões de intelectuais negras, indígenas e afrofeministas no que se refere a pensar as similaridades diante dos diferentes processos de opressão.

Outro ponto que este artigo se propõe a tratar é tomar e ler a necropolítica e a bionecropolítica por um outro lugar que não sejam apenas as reflexões de intelectuais homens, bem como ampliar o debate nesse campo no qual, na maioria das discussões, o caráter preponderante são análises que têm no estatal lugar privilegiado. Não significa retirar o Estado, pelo contrário, os assassinatos de Berta Cáceres e Marielle Franco, assim como a prisão de Milagro Sala, têm relação direta com a máquina estatal. Nosso objetivo é ir além dessa dimensão, tentando fazer ver e dizer dimensões micropolíticas, históricas, culturais que alimentam cotidianamente o projeto necropolítico, principalmente o racismo e o sexismo que maquinam a partir da racialização do gênero e da genderização da raça.

Nesse sentido, pensar uma bionecropolítica genderizada tem como objetivo ampliar os debates e enfoques no que tange à noção de necropolítica marcada, na maioria das vezes, pela ausência elou anulação de um olhar a partir das relações de gênero, silenciando e/ou apagando as formas como a necropolítica atravessa os corpos e as vidas das mulheres negras, indigenas e/ou racializadas. Assim, propomo-nos a olhar por dentro da necropolítica ou da bionecropolítica a partir das experiências de mulheres 
no que temos chamado de bionecropolítica genderizada, tentando fazer ver e dizer não apenas as violências, mas os processos de resistências viscerais protagonizados pelas mulheres negras e indígenas, sua força e a capacidade de reorganização dos campos de lutas na Améfrica (GONZALEZ, 2018).

Por fim, a frase "Parem de nos matar", que compõe parte do título deste artigo, reflete nossas inquietações. Tomamos emprestada tanto do livro da escritora brasileira negra Cidinha da Silva (2019), em que ela desenvolve várias crônicas mostrando as faces do extermínio de negras(os) em contextos brasileiros, quanto de diferentes movimentos sociais que acabaram por tomar essa frase como um slogan na luta contra diversas formas de violência de gênero e sexual, ganhando força na hastag \#paremdenosmatar. Parem de nos matar é uma convocação cotidiana de muitas mulheres, assim como o slogan "ni una menos" (nenhuma a menos), que se tornou forte ultimamente na Argentina. Ambas denunciam as violências que atingem as mulheres e organizam diferentes campos de lutas que seguem pedindo justiça para Berta Cárceres e Marielle Franco (e muitas outras que tiveram suas vidas tiradas pelo necropoder) e a liberdade imediata de Milagro Sala e outras ativistas que têm se tornado presas políticas. Esse é um movimento multitudinário levado por diferentes mulheres nos mais diversos contextos latino-americanos, espaço no qual o número de atentados à vida e de assassinatos de militantes dos direitos humanos assume proporções assustadoras (ANISTIA INTERNACIONAL, 2018).

\section{Colonialidade e colonialidade e gênero}

É impossivel desenvolver uma reflexão que tente construir um em-comum entre os três acontecimentos, sem recorrermos a uma análise sobre os elementos de colonialidade que são forjados e reatualizados constantemente em cenários latino-americanos. Nesse sentido, é impossivel separar a colonialidade da modernidade e vice-versa, assim como é impossivel apagar, do centro dessa engrenagem, as relações étnico-raciais ou a ficção racial (FOUCAULT, 2005; MBEMBE, 2014; QUIJANO, 2002, 2005). Assim, esta seção tem como objetivo trazer o debate sobre colonialismo/ colonialidade sinalizando como, a partir deste, uma bionecropolítica se constituiu operando a legitimação de extermínios, entre estes, os de mulheres que, em sua grande maioria, são negras, indigenas e/ou racializadas que se colocam mediante o cis-heteropatriarcado racista que se faz presente por meio de um "sistema moderno/colonial de gênero", marcado pela diferença colonial (LUGONES, 2008, 2011). 
Podemos tomar como marco do que se convencionou chamar de colonialismo a chegada dos ditos colonizadores a estas terras, que hoje podemos localizar no território geográfico que denominamos como a América Latina. A partir desse encontro, produziu-se uma expropriação total de todos os bens, costumes e até da vida dos que já habitavam essas regiões, tanto quanto, posteriormente, dos povos africanos que foram sequestrados, escravizados e trazidos para América Latina. Esse processo, marcado pela extrema violência e brutalidade, afetou todas as relações, inaugurando um novo eixo de dominação e, junto com ele, um novo eixo de exploração de recursos e produtos. A escravização e a servidão serviram para produzir mercadorias para o mundo inteiro, configurando-se uma organização servil e escravocrata e que continua sendo revivificada de diferentes formas, principalmente em lugares periféricos do mundo. Essa nova ordem mundial é o que o pensador peruano Aníbal Quijano (2005) chamou de modernidade-colonialidade. A partir de então, um novo padrão de poder foi instituído mundialmente, segundo o qual

\footnotetext{
a América se constitui como o primeiro espaço/tempo de um padrão de poder de vocação mundial e, desse modo e por isso, como a primeira id-entidade da modernidade. Dois processos históricos convergiram e se associaram na produção do referido espaço/tempo e estabeleceram-se como os dois eixos fundamentais do novo padrão de poder. (QUIJANO, 2005, p. 117, tradução nossa).
}

Essa violência inaugural, podemos afirmar, perpetua-se até nossos dias, expressa-se por meio de diferentes linhas de saber-poder que atuam sistematicamente nas tentativas de subalternização de povos, comunidades e grupos fora dos lugares de privilégio do poder, ou seja, o privilégio racial, de gênero, de sexualidade, de origem, de território, entre tantos outros. Desde o século XV até a atualidade, temos visto como essas práticas de violência têm se sofisticado e se modificado, transformando-se em algo mais duradouro e estável, que podemos chamar de colonialidade (QUIJANO, 2002).

Assim, a colonialidade do poder é um dos elementos constitutivos do padrão global do poder capitalista. Funda-se na imposição de uma classificação racial/étnica da população do mundo como peça central de poder e opera em cada um dos planos, âmbitos e dimensões materiais, subjetivas e intersubjetivas da existência cotidiana em escala social. Com a invenção de América, o sistema capitalista se fez mundial, tendo como grandes lugares de circulação o Atlântico e o que conhecemos como Europa. Com o novo padrão 
de dominação, instauram-se a colonialidade e a modernidade. Podemos afirmar, então, que, com a invenção da América e América Latina, o capitalismo se torna um fenômeno mundial e eurocentrado, em que a colonialidade e modernidade se instalam e perduram até nossos dias como eixos centrais do poder (QUIJANO, 2005).

Foi no contexto de colonialismo que a noção de raça emergiu e ganhou contornos e relevância no que se refere à classificação dos povos que já habitavam essas regiões, bem como os africanos escravizados que chegariam posteriormente, constituindo não apenas uma forma de classificação, mas um modo de garantir legitimidade nas relações de dominação que se instituíram, transformando-se num padrão mundial de poder. "Desse modo, a raça se converteu no primeiro critério fundamental para a distribuição da população mundial nos níveis, lugares e papéis na estrutura de poder da nova sociedade. Em outras palavras, no modo básico de classificação social universal da população mundial" (QUIJANO, 2005, p. 118, tradução nossa).

Funda-se, assim, uma nova cosmovisão e práticas sociais que classificam e tutelam os povos indigenas e as populações africanas escravizadas, considerando-os seres inferiores e inaugurando uma forma de violência sem precedentes na história. Podemos afirmar que essas práticas se mantiveram ao longo do tempo e estão vigentes na nossa atualidade. Tais violências nos constituem e atravessam toda a América Latina, que se caracteriza como sociedades racistas, violentas e fóbicas, sociedades que constantemente reatualizam elementos de colonialidade, ideias e práticas de superioridade (branquidade), naturalização das desigualdades e assimetrias sociais, bem como a naturalização do extermínio de determinadas populações, grupos e pessoas.

Dessa forma, pensar elementos de um em-comum em contextos latino-americanos nos convoca a trazer a etnia e a raça como espinha dorsal, mesmo salientando sua dimensão ficcional, como já foi discutido anteriormente, para compreensão dos fenômenos, principalmente aqueles sobre os quais este texto se propõe a refletir. Todavia algumas questões saltam imediatamente, quando estamos nos propondo a olhar a colonialidade/modernidade: como ficam essas reflexões quando trazemos as relações de gênero para pensar o padrão de poder mundial? Quando trazemos para o centro das reflexões os modos de vidas das mulheres indígenas, negras e/ou racializadas? Quando interseccionalizamos raça e gênero, que configurações de poder se produzem, tanto no âmbito macro quanto micropolítico? 
Mesmo tendo, em suas reflexões, considerado que o sexo, seus produtos e a reprodução da espécie fazem parte, de forma articulada, das redes de poder, exploração e dominação mundial, Quijano (2009), além de não desenvolver uma análise que levasse em consideração uma perspectiva interseccional que fizesse ver e dizer sobre as mulheres que tiveram sobre seus corpos-subjetividades a brutalidade da colonialidade por meio de diferentes processos de subalternização, afirmava que

a "racialização" das relações de poder entre as novas identidades sociais e geoculturais foi o sustento e a referência legitimadora fundamental do carácter eurocentrado do padrão de poder, material e intersubjetivo. Ou seja, da sua colonialidade. Converteu-se, assim, no mais específico dos elementos do padrão mundial do poder capitalista eurocentrado e colonial/moderno e atravessou - invadindo - cada uma das áreas da existência social do padrão de poder mundial, eurocentrado, colonial/ moderno. (QUIJANO, 2009, p. 107, tradução nossa).

Partindo da importância das ponderações de Quijano, mas também de certa insuficiência num olhar mais interseccional, algumas feministas de cor e latino-americanas têm construído reflexões que alargam as discussões sobre modernidade/colonialidade. Maria Lugones (2008), quando se propõe a olhar as reflexões de Quijano, que se restringem ao sexo, seus recursos e produtos, aponta que:

No entanto, a colonialidade não se refere somente à classificação racial. É um fenômeno que abrange, pois se trata de um dos eixos do sistema de poder e, como tal, permeia todo controle de acesso sexual, autoridade coletiva, trabalho, subjetividade/ intersubjetividade. Dito de outra maneira, todo controle do sexo, subjetividade, autoridade e o trabalho estão expressados na conexão com a colonialidade. (LUGONES, 2008, p. 79, tradução nossa).

Dessa forma, Lugones (2008) contribui para redimensionar as discussões sobre colonialidade. Inicialmente, evidencia que a redução do gênero à organização do sexo, seus recursos e produtos é insuficiente para pensar as complexidades dessas relações. Movida por uma lente epistemo-metodológica interseccional e decolonial, ressalta que todas/os somos racializadas/ os e genderizadas/os, no entanto nem todas/os são dominadas/os e inferiorizadas/os nesse processo, colocando em evidência o grupo das mulheres brancas marcadas pelo privilégio hegemônico de poder, evidenciando que o eixo de colonialidade, como apresentado por Aníbal Quijano, apesar de 
apresentar uma lógica correta, "não é suficiente para dar conta de todos os aspectos de gênero" (LUGONES, 2008, p. 82, tradução nossa); entendendo que "a raça não é nem mais mítica nem mais fictícia que o gênero ambos são ficções poderosas" (LUGONES, 2008, p. 94, tradução nossa). Esse movimento epistemo-metodológico para tornar importantes os lados visíveis, mas também ocultos no entrelaçamento entre raça e gênero e gênero e raça em contextos latinos, Lugones (2008) chamou de sistema de gênero colonial/moderno.

Tomamos essa ideia intercessora como um dos espaços possiveis para entendermos as possibilidades de conexões entre os assassinatos de Berta Cáceres e Marielle Franco e a prisão de Milagro Sala. Nesses três acontecimentos, é impossivel separar etnia/raça/gênero, pois há as marcas da colonialidade sobre seus corpos, subjetividades e processos intersubjetivos. Foi também o reconhecimento desse lugar em que as tentativas de subalternização não cessam de operar, em que Berta, Marielle e Milagro construíram um lugar de força e luta, reconhecendo uma dimensão maior, comunitária, uma luta que rompe fronteiras e evoca uma dimensão amefricana, mesmo reconhecendo os processos singulares de origem, de histórias, geracionais, entre outros.

\section{A bionecropolítica genderizada}

Tomando a discussão apresentada, a produção da necropolítica enquanto diagrama de poder é indissociável do colonialismo/colonialidade. A ideia de necropolítica se tornou popular a partir do ensaio "Necropolítica", do pensador camaronês Achille Mbembe, publicado pela primeira vez em 2003, na Revista Public Culture. Desde então, tem sido usada na compreensão das relações de poder nos lugares marcados pelo colonialismo, neocolonialismo e pela colonialidade. Partindo da questão "quem pode e quem deve morrer", Mbembe (2018) retoma o tema da soberania para pensar a respeito das relações de controle sobre a mortalidade e como o poder de matar, deixar viver ou expor à morte é a tônica da política contemporânea. Retoma, nesse sentido, as reflexões foucaultianas sobre o biopoder e a biopolítica, destacando a insuficiência desses conceitos na compreensão profunda de diferentes contextos fora do domínio eurocentrado.

No centro de suas análises, encontra-se o sistema colonial, a plantation (plantação) e o processo escravocrata como figuras emblemáticas da necropolítica. Seguindo esse raciocínio, o autor recupera as discussões sobre a noção de exceção, mostrando como, nos lugares marcados pelo 
colonialismo, a exceção se fez presente como forma legítima, tanto política quanto jurídica. Ao recorrer às reflexões de Frantz Fanon (2015), na obra Os condenados da terra, o autor evidencia que "em si, as colônias são o local, por excelência, onde os controles e as garantias da ordem jurídica podem ser suspensos - a zona onde a violência do Estado de Exceção está condenada a operar ao serviço da civilização" (MBEMBE, 2017, p. 127). Essa marca colonial nos acompanha, perfaz as construções das democracias latinas, sendo impossivel separar a constituição de certa ordem democrática das relações coloniais e escravistas.

Aqui, o racial passa a ser um elemento fundamental na configuração e na dinâmica da necropolítica, de acordo com a qual não apenas os povos escravizados, mas inúmeras comunidades indígenas que aqui habitavam foram o substrato sob o qual a máquina necropolítica pôde se fazer presente e funcionar. Por isso, "em larga medida, o racismo é o motor do princípio necropolítico" (MBEMBE, 2017, p. 65).

Nesse cenário, a vida sofre uma mudança consubstancial no que refere ao valor, produzindo vidas cujo valor passa a estar fora da economia, configurando-se numa vida supérflua, por isso exterminável, tornando-se "uma morte à qual ninguém se sente obrigado a responder" (MBEMBE,2017, p. 65). Nesse processo, "fazer morrer, deixar morrer" passa a ser a máxima que regula as relações de poder, sejam essas estatais ou não. Na necropolítica, "são poucos os sofrimentos considerados injustos. Não existe nem culpabilidade, nem remorso, nem reparação. Tal como não existem injustiças que se devem reparar ou tragédias que possam evitar" (MBEMBE, 2017, p. 66). É contra essa característica brutal da necropolítica que diferentes manifestações têm trazido a ideia de justiça e reparação, principalmente justiça e reparação étnica, racial e de gênero como processos de resistências viscerais.

No que se refere à noção de bionecropolítica, partimos das reflexões de Lima (2018), quando propõe uma torção nas noções foucaultianas de biopoder e biopolítica, acoplando a elas a necropolítica como uma das formas - talvez a principal - pela qual os poderes se organizaram fora dos contextos eurocentrados. Assim,

saindo de análises centradas em contextos europeus, "Necropolítica" fornece ferramentas para pensarmos a forma de constituição de diagramas de poder não apenas nos contextos pós-coloniais de Áfricas, mas também nos processos de colonização, 
neocolonização, descolonização e nos traços de colonialidade que ainda imperam com força nos contextos latino-americanos, caribenhos e brasileiros. Dessa forma, promove uma mudança tanto analítica quanto na forma de olhar e tomar alguns processos históricos que têm nos contextos europeus o foco territorial e a primazia analítica dos eventos. A partir desse deslocamento, o holocausto deixa de ser o modelo paradigmático de genocídio de povos e populações. O processo de colonização e neocolonização e, consequentemente o extermínio das populações indígenas, dos povos autóctones e o sequestro e escravização dos povos de Áfricas passam a ser o centro do debate bio-necropolítico. Nesses devires, a vida (a bios) precisa ser tomada de uma perspectiva racializada, levada ao máximo de sua importância, produzindo movimentos de vergonha, culpa, reparação. (LIMA, 2018, p. 26).

Dessa forma, entendendo o biopoder, a biopolítica e a necropolítica como formas de saber/poder que organizam a vida/morte, a morte/vida e a morte/ morte, Lima (2018) propõe a noção de bionecropolítica como um acoplamento de poder à tríade disciplina-biopoder-biopolítica. Entendemos aqui que, na organização dos modos de vida em contextos latinos, é possivel observar elementos do biopoder (a exemplo de inúmeras reatualizações do poder disciplinar, por exemplo, que continuam exercendo sobre corpos controle e práticas de governo); elementos de biopolítica que têm as populações como lugar de controle e governamentalidade (principalmente as populações que são colocadas em situações de vulnerabilidades); e a necropolítica, ou seja, formas de organização e de governo que têm, nas mortes e no extermínio, um dos elementos principais, conformando-se numa grande maquinaria (macro e micropolítica), nos lugares marcados pelo colonialismo ou neocolonialismos, reafirmando hierarquias e processos de subalternização (LIMA, 2019).

Nessa maquinaria que chamamos aqui de bionecropolítica genderizada e que tem como foco as mulheres negras, indígenas e racializadas, gostaríamos de destacar alguns elementos que são congêneres aos dispositivos analíticos que balizam nossas análises: (a) as transformações nas relações de soberania; (b) o racismo como motor da bionecropolítica genderizada; e (c) morte/vida como o centro da política e das guerras atuais.

Inicialmente, o tema da soberania é fundamental para a compreensão do funcionamento da bionecropolítica, na medida em que o exercício da soberania significa o controle sobre a mortalidade. Destacamos, nos cenários atuais, mudanças nas relações de soberania cujo projeto central não está mais na luta por autonomia, "mas antes a instrumentalização generalizada da existência humana e a destruição material de corpos humanos 
e populações" (MBEMBE, 2017, p. 111). Esse movimento faz que nos perguntemos, assim como pergunta Achille Mbembe (2018) quando questiona em relação à soberania, nas páginas inicias de Necropolítica, "quem é o sujeito dessa lei?": "quem matou Marielle?"; "quem mandou matar Marielle?"; "quem mandou matar Berta Cáceres?"; "quem mandou prender a ativista indígena Milagro Sala?". Esse movimento, de tomar a soberania no sentido atual, torna visiveis e diziveis um poder à margem da lei, um constante estado de exceção, operando a serviço da civilização, a preponderância das relações de inimizade e uma guerra sem fim (MBEMBE, 2017, 2018), na qual soberana(o) é qualquer uma(um) que se arvore no direito legítimo de eliminar a(o) outra(o).

As práticas racistas são outro elemento que compõe a bionecropolítica. Por esse viés, é preciso entender por racismo relações de poder que classificam, hierarquizam, nominam, excluem, exterminam um conjunto de outros que geralmente estão fora dos privilégios raciais (a branquidade como norma hegemônica), de classe, territoriais, de gênero, entre outros. Não custa lembrar que, quando falamos de racismo, não estamos evocando uma noção universalista de raça nem de etnia, mas compomos com Coates (2015, p. 19) quando afirma que "a raça é a filha, e não a sua mãe". Por outro lado, junta-se a tais reflexões a presença cada vez mais insidiosa de um nanorracismo.

Esta forma narcótica do preconceito em relação à cor expressa nos gestos anódinos do dia a dia, por isto ou por aquilo, aparentemente inconscientes, numa brincadeira, numa alusão ou numa insinuação, num lapso, numa anedota, num subentendido e, é preciso dizê-lo, numa maldade voluntária, numa intenção maldosa, num atropelo ou numa provocação deliberada, num desejo obscuro de estigmatizar e, sobretudo, de violentar, ferir e humilhar, contaminar o que não é considerado como sendo dos nossos. (MBEMBE, 2017, p. 95).

Outras/novas práticas racistas são forjadas constantemente, disputando vários sentidos de raça. Esses elementos estão presentes nos assassinatos de Berta Cáceres e Marielle Franco, bem como na prisão de Milagro Sala, vidas essas atravessadas por racismo, por isso valem menos. As práticas racistas transpassadas por um nanorracismo cotidiano constituem um dos elementos em-comum nos dispositivos que conduzem nossas reflexões. $\bigcirc$ preconceito, marcado pelo ódio às comunidades indígenas nos contextos latino-americanos com o mesmo sentimento em relações às populações negras, atravessa o assassinato de Berta Cáceres e o de Marielle Franco, assim como a prisão 
de Milagro Sala, relações marcadas pelo ódio, pelo preconceito étnico-racial e pela misoginia, pois, além do fato de serem indígenas e negra, eram, antes de tudo, mulheres.

Por fim, outro elemento que nos parece central nas análises desses três episódios e que constituem elementos na bionecropolítica diz respeito à morte/vida como o centro da política e das guerras atuais. Seguindo esse raciocínio, inicialmente, ressaltamos que bios (a vida) sofre violentamente uma mudança naquilo que se configurou como o nascimento do biopoder, como já dito por Foucault (2014), em que, para fazer vidas serem majoradas, outras precisavam ser eliminadas. Talvez o que tenha crescido é, cada vez mais, a legitimação do extermínio de uma carne diferente, corpos- subjetividades que constam como passiveis de serem liquidados porque compõem a ideia de uma vida supérflua dentro de um conjunto histérico e fantasmagórico assolado por delírios de pureza, por relações de inimizade e pelo desejo de extermínio. As mulheres indígenas e negras fazem parte de uma grande engrenagem de fantasia colonial que opera, por um lado, pela hiperssexualização, mas, por outro, empurra-as para zonas de não ser.

Esse cenário está ancorado num processo de guerra constante segundo o qual, "sob as condições do capitalismo neoliberal, a política se converterá em uma guerra mal sublimada. Esta será uma guerra de classe que nega sua própria natureza; uma guerra contra pobres, uma guerra racial contra as minorias, uma guerra de gênero contra as mulheres" (MBEMBE, 2016, tradução nossa). Esse contexto de guerra sem fim traduz muito o que transversaliza a vida de Berta, Marielle e Milagro em um contexto marcado pela política da guerra às minorias étnico-raciais, aos pobres, às mulheres e a todas(os) aquelas(es) que tensionam o cis-heteropatriarcado como modelo dominante de organização política. Os acontecimentos que marcam a vida das três se inserem nesse contexto neoliberal. As denúncias das opressões, desigualdades, violências e assimetrias, e, acima de tudo, a luta por justiça e reparação étnico-racial e de gênero são marcas em suas existências.

Por outro lado, acoplada a essa máquina que aqui estamos chamando de bionecropolítica, trazemos as relações de gênero para pensar essa maquinaria cujo motor é o racismo e, consequentemente, as noções de raça que se forjam, são reatualizadas e disputadas diariamente. Pensar uma bionecropolítica de gênero é entender que "raça e gênero são inseparáveis onde 'raça' não pode ser separada de gênero nem o gênero pode ser separado da 'raça'. A experiência envolve ambos porque construções racistas baseiam-se 
em papéis de gênero e vice-versa, e o gênero tem um impacto na construção de 'raça' e na experiência do racismo" (KILOMBA, 2019, p. 94).

Essa ideia não é recente no campo de reflexões das pensadoras negras. $\mathrm{Na}$ longa história da produção de mulheres negras, feministas ou não, a relação entre raça, gênero e também sexualidade estiverem sempre presentes. Destacamos as reflexões das pensadoras, intelectuais e feministas brasileiras e negras, como Lélia Gonzalez (2018) e Sueli Carneiro (2011), além de feministas negras estadunidenses, como bell hooks, com inúmeros textos que tomam raça, gênero e sexualidade como categorias centrais; Patricia Hill Collins (2019), com importantes discussões sobre a política sexual e as mulheres negras; Angela Davis $(2016,2017)$ com reflexões que incorporaram a classe como um eixo de opressão imprescindivel nas reflexões sobre raça e gênero; Audre Lorde (2019), entre muitas outras. Lembramos aqui o texto seminal "Manifesto do Rio Combahee", escrito por militantes negras e lésbicas negras em 1977, quando já nos apontava "o compromisso ativo contra a opressão racial, sexual, heterossexual e de classe" (COMBAHEE RIVER COLLECTIVE, 2012, p. 75, tradução nossa).

que as inquietações aqui tentam apontar é como as relações de gênero constituem uma das linhas de força que perpassam os diagramas bionecropolíticos. Atravessados por esses diagramas de poder, encontram-se os corpos-subjetividades de mulheres que se tornam mais propícias às vulnerabilidades, na medida em que, a partir de diferentes lugares, tornam-se ativistas políticas e passam a interpelar publicamente os poderes hegemônicos do cis-heteropatriarcado. Berta Cáceres, Milagro Sala, Marielle Franco e muitas outras fazem parte de processos em que o racismo/sexismo acaba por reforçar um lugar possivel de extermínio.

Dentro desse quadro analítico, as relações de gênero constituem uma das linhas de força no diagrama bionecropolítico, cortando os contextos latino-americanos, ganhando contornos singulares, mas conservando pare-

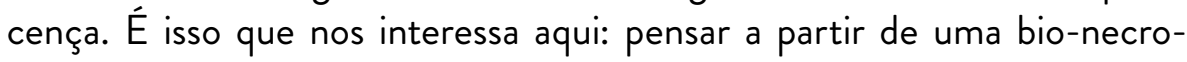
política genderizada. Entender, antes de tudo, que esses acontecimentos são singulares, engendram lutas singulares, mas são atravessados pela força da colonialidade que tem tomado os corpos-subjetividades de mulheres negras, indigenas, quilombolas, ribeirinhas, trabalhadoras rurais, mulheres das florestas e campos, das favelas e subúrbios como espaço privilegiado de atuação. Pensar a partir e com uma bionecropolítica genderizada possibilita pensar um em-comum e, consequentemente, pensarmos também em 
estratégias, sejam de resistência, de reexistência ou de persistência a esse tempo sempre marcado pela brutalidade.

\title{
Por uma Améfrica Ladina
}

Sabemos que a América é uma invenção e, junto com ela, suas subdivisões e, principalmente, o que se convencionou chamar de América Latina, consequência de estruturas geopolíticas que têm sido reatualizadas há 520 anos, marcadas, como já discutido anteriormente, pela colonialidade/modernidade que teve no aspecto racial não apenas a estigmatização dos povos indígenas e africanos que foram escravizados e trazidos para a América Latina por espanhóis e portugueses, mas um sistema de subalternização que afetou profundamente as relações sociais, subjetivas e intersubjetivas. Marcado por uma pluralidade cultural, diferentes linguas, costumes, formas de organização, entre outros aspectos da vida social, o eixo da dominação perpassou diferentes lugares, povos e comunidades. Assim:

\begin{abstract}
Como conceito, a América é inseparável da ideia de modernidade, ambas são a representação de projetos imperiais e designados para o mundo, criados por atores e instituições europeias que os levaram a cabo. A invenção da América foi um dos pontos nodais que permitiram criar as condições necessárias para expansão imperial e para a existência de um estilo de vida europeu que funcionou como modelo de progresso da humanidade. [...] Um momento crucial na história, um momento em que as exigências da modernidade como meta para obter a salvação impuseram um conjunto específico de valores cuja implementação se apoiava na lógica da colonialidade. (MIGNOLO, 2005, p. 32, tradução nossa).
\end{abstract}

No entanto propomos acoplar as discussões de pensadores decoloniais às produções da intelectual brasileira e feminista negra Lélia Gonzalez, tanto no que se refere às reflexões que culminaram na ideia de Améfrica Ladina construindo um conceito-intercessor que nos fornece possibilidades interessantes de pensar as similaridades nas experiências de mulheres indigenas e negras em contextos latinos, os "ameríndios e aos africanos [...] subordinados a uma latinidade que legitima sua inferiorização" (GONZALEZ, 2018, p. 308) - quanto à ideia de um feminismo afrolatinoamericano, espaço no qual tanto ameríndias quanto amefricanas construíram uma agenda comum de percepção da opressão, bem como de construção de respostas ativas a esta. Particularmente, esses são pontos que nos interessam, ou seja, perceber e ressaltar como a ideia de latinidade opera um processo de subordinação, 
a legitimação deste e, consequentemente, a legitimação de diferentes processos de extermínio, produzindo uma soberania latina que atua a todo instante com a construção da(o) inimiga(o) que é racializadas(o) e genderificada(o).

Partindo da ideia de que os processos de formação histórico-cultural do Brasil não são exclusivamente europeus e branco, inclusive do ponto de vista inconsciente, Lélia Gonzalez expõe tantos os aspectos ameríndios quanto africanos como preponderantes na nossa formação, confugurando-nos muito mais uma Améfrica Ladina do que uma América Latina, atingindo todos os habitantes. Negras(os) ou não, indígenas ou não, todos que habitamos este continente somos amefricanas(os). Por outro lado, não vivemos todos da mesma forma essa experiência, sendo as(os) indígenas e as(os) africanas(os), bem como suas(seus) descendentes, alvos privilegiados dos processos de subalternização em diferentes esferas da vida. Esse processo foi sustentado pelo mito da democracia racial, pelo imperativo da miscigenação e por um processo assimilacionista que tentou invisibilizar a dimensão ameríndia e amefricana do Brasil e da América Latina, em que, "embora pertençamos a diferentes sociedades do continente, sabemos que o sistema de dominação é o mesmo em todas elas" (GONZALEZ, 2018, p. 330).

Opondo-se a uma série de termos construídos principalmente por intelectuais negros estadunidenses, como afroamerican ou african-american, Lélia Gonzalez se volta para experiências internas à noção de amefricanidade, a partir da pluralidade de experiências étnico-raciais, que podem partilhar similaridades e um "em-comum" que antecedem, inclusive, à chegada dos ditos colonizadores por meio de inúmeras experiências na américa pré- colombiana. "Por conseguinte, o termo amefricanas/amefricanos designa toda uma descendência: não só dos africanos trazidos pelo tráfico negreiro, como a daqueles que chegaram à AMÉRICA muito antes de Colombo" (GONZALEZ, 2018, p. 330). Assim nos diz Gonzalez (2018, p. 329):

As implicações políticas e culturais da categoria de Amefricanidade (Amefricanity) são, de fato, democráticas; exatamente porque o próprio termo nos permite ultrapassar as limitações de caráter territorial, linguístico e ideológico, abrindo novas perspectivas para um entendimento mais profundo dessa parte do mundo onde ela se manifesta: a AMÉRICA e como um todo (Sul, Central, Norte e Insular). Para além de seu caráter puramente geográfico, a categoria de amefricanidade incorpora todo um processo histórico de intensa dinâmica cultural (adaptação, resistência, reinterpretação e criação de novas formas) que é afrocentrada. 
Ainda sobre amefricanidade, complementa mais à frente:

Seu valor metodológico, a meu ver, está no fato de permitir a possibilidade de
resgatar uma unidade específica, historicamente forjada no interior de diferen-
tes sociedades que se formam numa determinada parte do mundo. Portanto, a
Améfrica enquanto sistema etno-geográfico de referência é uma criação nossa e
de nossos antepassados no continente em que vivemos inspirados por modelos afri-
canos. (GONZALEZ, 2018, p. 330).

Portanto as reflexões apontadas contribuem para o exercício de pensar modos de vidas e trajetórias das populações que têm sido ostensivamente subalternizadas e invisibilizadas e se somam a outras reflexões da autora que nos ajudam a entender melhor como a colonialidade foi sendo marcada por uma bionecropolítica que atinge, de forma severa, as indigenas e negras, tornando evidente seu caráter não apenas racializado, mas genderizado.

No texto "Por um feminismo afrolatinoamericano", publicado orginalmente em 1988, ano que marca o centenário da Lei Áurea no Brasil, culminando em comemorações por todo o país, no que se chamou "cem anos de abolição", a partir de questionamentos sobre a situação de negros e negras no Brasil, Lélia Gonzalez (2018, p. 307) nos provoca quando diz que:

\footnotetext{
Para nós, mulheres e homens negros, nossa luta pela libertação começou muito antes desse ato formal e se estende até os dias atuais. Nosso compromisso, portanto, é no sentido de que a sociedade brasileira, refletindo sobre a situação do segmento negro [...] pode se transformar em si mesma e reconhecer, em suas contradições internas, as profundas desigualdades raciais que a caracterizam. Nesse sentido, as outras sociedades que também compõem essa região, este continente chamado América Latina, quase não difere da sociedade brasileira.
}

Mais uma vez, o projeto intelectual de Gonzalez contribui para pensarmos a América Latina não como algo homogêneo, igual, mas como um projeto bionecropolítico marcado pela violência, pela brutalidade, pelo aniquilamento, pelas desigualdades e assimetrias. Os assassinatos de Berta Cáceres e Marielle Franco, assim como a prisão de Milagro Sala, como já dissemos anteriormente, têm singularidades históricas, geográficas, culturais e que envolvem elementos e dinâmicas locais. No entanto são transpassados por uma flecha que rompe as barreiras do tempo e do espaço, atravessa fronteiras, porque têm a marca da violência, da brutalidade, 
da opressão e do extermínio, em que "a amefricanidade se refere à experiência comum de mulheres e homens negros na diáspora e à experiência de mulheres e homens indígenas contra a dominação colonial" (CARDOSO, 2014, p. 971).

Ainda nesse texto, Gonzalez faz um resgaste muito interessante dos movimentos de mulheres negras ( $M N)$, dos movimentos indigenas $(M I)$ e étnicos (ME) recuperando, a partir desses movimentos, diferentes processos na América Latina com a participação de mulheres como construções de redes, a exemplo do "Taller de Mulheres das Américas", e "Dawn/Mudar"5; encontros internacionais como o ocorrido em Nairóbi, além do "Il Taller de Mulheres das Américas", que ocorreu na cidade do Panamá. Ressaltamos a participação de ativistas negras brasileiras presentes nesse processo, como da própria Lélia Gonzalez e outras que atuavam naquele momento em diferentes grupos, destacando, em 1975, "o encontro histórico de latinas que marcaria o início do MM no Rio de Janeiro" (GONZALEZ, 2018, p. 317). Esses movimentos tinham uma marca em comum:

\begin{abstract}
Para nós, amefricanas do Brasil e de outros países da região - assim como para as ameríndias - a conscientização da opressão ocorre antes de qualquer coisa, pelo racial. Exploração de classe e discriminação racial constituem o elemento básico da luta comum de homens e mulheres pertencentes a uma etnia subordinada. A experiência histórica da escravização negra, por exemplo, foi terrivel e sofridamente vivida por homens ou mulheres, fossem crianças, adultos ou velho. E foi dentro da comunidade escravizada que se desenvolveram formas político-culturais de resistência que hoje permitem continuar uma luta plurissecular de liberação. A mesma reflexão é válida para as comunidades indigenas. Por isso, nossa presença nos ME é bastante visível; aí nós, amefricanas e ameríndias, temos participação ativa e, em muitos, casos somos protagonistas. (GONZALEZ, 2018, p. 316).
\end{abstract}

Assim, destacamos que essa experiência de violência e subordinação mobiliza tanto o racial como a classe social, que atravessa relações gênero e geracionais, rompe fronteiras e constitui uma experiência histórica, uma ferida colonial (KILOMBA, 2019) que atinge as populações indígenas e negras. No entanto é no centro dessas experiências vividas que os processos de resistências são constituídos a partir da tomada de consciência das

5 Sigla de Alternativas de Desenvolvimento com Mulheres por uma Nova Era. Esse movimento surgiu na década de 1980, a partir de inúmeras iniciativas de mulheres, entre estas latino-americanas, com o objetivo de analisar a situação das mulheres no mundo e formular uma visão de sociedade alternativa (DEVELOPMENT ALTERNATIVES WITH WOMEN FOR A NEW AGE, 1985). 
opressões vivenciadas cotidianamente, principalmente pelas mulheres, opressões estas impossiveis de separar raça/gênero/sexualidade ou, como bem problematizou Gonzalez (2018), o racismo e o sexismo. Como aponta a intelectual negra Thula Pires (2019, p. 73), "a amefricanidade valoriza e resgata saberes produzidos por mulheres negras e indígenas e os qualifica para informar outras práticas, outra gramática de direitos". Nesse campo de lutas ativo, Berta Cáceres, Marielle Franco e Milagro Sala foram e são protagonistas do reconhecimento dessa colonialidade, de seus eixos de opressões e violências, assim como forjaram e forjam outra gramática de direitos. Suas vidas foram e são marcadas pela persistência ao tempo dos assassinos.

\section{A persistência ao tempo dos assassinos}

Não nos resta outro caminho senão lutar. Berta Cáceres

Persistência é um substantivo feminino que significa, entre tantas acepções, qualidade do que dura, do que persiste. Tem, entre seus sinônimos, a perseverança, a constância, a tenacidade. Falar da persistência, ao tempo dos assassinos, é falar de mulheres e homens que, sob a égide da subalternização - esse necrotempo - que os condena, a priori, à inexistência, têm persistido na construção de si próprias(os) e de um mundo possivel para si e para todas(os) marcadas(os) pela força da colonialidade e da bionecropolítica.

Achille Mbembe (2014), no último capítulo de Crítica da razão negra, denominado "Existe um só mundo", chama atenção sobre a existência de apenas esse mundo e do desejo de todas(os) de nele desfrutar de uma vida plenamente vivida. Contudo ressalta que, "enquanto houver secessão em relação à humanidade, não será possível a economia da restituição, da reparação ou da justiça. Restituição, reparação e justiça são as condições para a elevação coletiva em humanidade" (MBEMBE, 2014, p. 309). Berta Cáceres e Marielle Franco sabiam disso. Milagro Sala sabe disso. Essa é uma luta coletiva, que se faz fazendo, uma luta em que a descolonização não é uma palavra, mas são atos constantes que podem custar a própria vida.

Existe um aforismo presente no povo Aymara, retomado nas reflexões da intelectual, socióloga e feminista Silvia Rivera Cusicanqui (2019, tradução nossa), que diz o seguinte: "Quipnayra uñtasis sarnaqapxañani”, 
traduzido como "olhando atrás e adiante, podemos caminhar no presente futuro. [...] que o passado está diante de nós. Isso é muito comum a muitas línguas indígenas. Há muitas línguas indígenas que concebem o passado como algo que tu vês pela frente; o futuro, no entanto, não o conheces e por isso está atrás, nas costas".

Essa imagem em que o tempo é dado pela força da anacronia e o passado assume um lugar à frente consegue traduzir o que temos chamado do tempo dos assassinos e da persistência a ele. Colocar o passado à frente é ver e antever as violências e brutalidades que nos marcam. É perceber que certas formas de opressões, principalmente o racismo - motor dessa maquinaria perversa - não ficou para trás. Ele surge e irrompe no presente, mas precisamos caminhar olhando atrás (o que ainda não conhecemos), num tempo presente-futuro, ou seja, olhar um futuro já condenado por esses tempos. Talvez nosso grande exercício seja lançar as mãos para trás e arrancar do futuro tudo - que nos assombra e que produz o aniquilamento de determinadas populações, grupos e pessoas. Isso só será possível, entre tantas coisas, por meio da justiça e da reparação étnico-racial e de gênero, imprescindivelmente.
À memória de Berta Cáceres e de Marielle Franco.
Pela Liberdade de Milagro Sala.

\section{Referências}

ANISTIA INTERNACIONAL. Informe 2017/18: o estado dos direitos humanos no mundo. Londres, 2018. Disponivel em: https://bit.ly/2YN2gR3. Acesso em: 2 abr. 2020.

CARDOSO, C. P. Amefricanizando o feminismo: o pensamento de Lélia Gonzalez. Revista Estudos Feministas, Florianópolis, v. 22, n. 3, p. 965-986, 2014. Disponivel em: https://bit.ly/3dJFHRd. Acesso em: 31 mar. 2020.

CARNEIRO, S. Racismo, sexismo e desigualdade no Brasil. São Paulo: Selo Negro, 2011.

COATES, T. Entre o mundo e eu. Rio de Janeiro: Objetiva, 2015.

COLLINS, P. H. Pensamento feminista negro: conhecimento, consciência e a política do empoderamento. São Paulo: Boitempo, 2019. 
COMBAHEE RIVER COLLECTIVE. Un Manifiesto feminista negro. In: PLATERO, R. L. Intersecciones: cuerpos y sexualidades en la encrucijada. Barcelona: Ediciones Bellaterra, 2012. p. 75-86.

CURIEL, O. Género, raza y sexualidad. Debates contemporáneos. In: CONFERENCIAMAGISTRALENELMARCODELAESPECIALIZACIÓN MAESTRÍA DE ESTUDIOS DE LA MUJER, 2011, Ciudad de México. Anais [...]. Ciudad de México: Universidad Autónoma Metropolitana Xochimilco, 2011. p. 1-26. Disponível em: https://bit.ly/2CSGfYo. Acesso em: 1 abr. 2020.

CUSICANQUI, S. R. Silvia Rivera Cusicanqui: "Tenemos que producir pensamiento a partir de lo cotidiano". [Entrevista cedida a] Kattalin Barber. Alice News, Coimbra, 20 fev. 2019. Disponivel em: https://bit.ly/2ZjJFLk. Acesso em: 29 mar. 2020.

DAVIS, A. Mulheres, raça e classe. São Paulo: Boitempo, 2016.

DAVIS, A. Mulheres, cultura e política. São Paulo: Boitempo, 2017.

DEVELOPMENT ALTERNATIVES WITH WOMEN FOR A NEW AGE. Development, crisis and alternatives visions: third world women's perspectives. Delhi: Dawn, 1985.

FANON, F. Os condenados da terra. Lisboa: Letra Livre, 2015.

FOUCAULT, M. Em defesa da sociedade. São Paulo: Martins Fontes, 2005.

FOUCAULT, M. História da sexualidade: a vontade de saber. Rio de Janeiro: Paz \& Terra, 2014.

GAMBETTA, J. B. Cuerpos subjetivados: miradas desde el Sur. 2019. Tese (Doutorado em Psicologia) - Universidade Federal Fluminense, Niterói, 2019.

GONZALEZ, L. Primavera para as rosas negras: Lélia Gonzalez em primeira pessoa. São Paulo: Diáspora Africana, 2018.

KILOMBA, G. Memórias da plantação: episódios de racismo cotidiano. Rio de Janeiro: Cobogó, 2019.

LIMA, F. Bio-necropolítica: diálogos entre Michel Foucault e Achille Mbembe. Arquivos Brasileiros de Psicologia, Rio de Janeiro, v. 70, p. 20-33, 
2018. Número especial. Disponivel em: https://bit.ly/31uaeQK. Acesso em: 31 mar. 2020.

LIMA, F. $\bigcirc$ trauma colonial e as experiências subjetivas de mulheres negras: raça, racismo, gênero e a produção de sofrimentos. In: PEREIRA. M. O.; PASSOS. R. G. Luta antimanicomial e feminismo: inquietações e resistências. Rio de Janeiro: Autografia, 2019. p. 68-84.

LORDE, A. Irmã outsider. Belo Horizonte: Autêntica, 2019.

LUGONES, M. Colonialidad y género. Tabula Rasa, Bogotá, n. 9, p. 73-101, jul./dez. 2008.

LUGONES, M. Hacia um feminismo descolonial. La Manzana de la Discordia, Barcelona, v. 6, n. 2, p. 105-119, 2011.

MBEMBE, A. Crítica da razão negra. Lisboa: Antígona, 2014.

MBEMBE, A. The age of humanism is ending. Mail \& Guardian, Johannesburg, 22 dez. 2016. Disponível em: https://bit.ly/38g4tY3. Acesso em: 1 abr. 2020.

MBEMBE, A. Políticas da inimizade. Lisboa: Antígona, 2017.

MBEMBE, A. Necropolítica. São Paulo: N-1 Edições, 2018.

MIGNOLO, W. La idea de América Latina: la herida colonial y la opción decolonial. Barcelona: Gedisa, 2005.

PIRES, T. Direitos humanos e Améfrica Ladina: por uma crítica améfricana ao colonialismo jurídico. Lasa Fórum, Pittsburgh, v. 50, n. 3, p. 69-74, 2019. (Dossiê El pensamiento de Lélia Gonzalez, um legado y um horizonte). Disponivel em: https://bit.ly/2NHDJpT. Acesso em: 31 mar. 2020.

QUIJANO, A. Colonialidade, poder, globalização e democracia. Revista Novos Rumos, Marilia, ano 17, n. 37, p. 1-25, 2002.

QUIJANO, A. Colonialidad del poder, eurocentrismo y América Latina. In: LANDER, E. (org.). La colonialidad del saber: eurocentrismo y ciencias sociales. Perspectivas Latinoamericanas. Buenos Aires: Clacso, 2005. p. 117-142. 
QUIJANO, A. Colonialidade do poder e classificação social. In: SANTOS, B. S.; MENESES, M. P. (org.). Epistemologias do Sul. Coimbra: GC Gráfica de Coimbra, 2009. p. 73-117.

SILVA, C. Parem de nos matar. São Paulo: Pólen, 2019.

Recebido em abril de 2020.

Aprovado em junho de 2020. 